Research Article

\title{
Prevalence and Risk Factors of Group B Streptococcus Colonization in Pregnant Women: A Pilot Study in Palestine
}

\author{
Mohammad Qadi (i), 1 Adham AbuTaha $\mathbb{D}^{1,2}$ Ro'ya Al-Shehab, ${ }^{3}$ Salsabil Sulaiman, ${ }^{3}$ \\ Abdallah Hamayel, ${ }^{3}$ Amjad Hussein, ${ }^{1}$ Shatha AbuTaha, ${ }^{3}$ Ayman Dawoud, ${ }^{2}$ \\ and Faizeh Hussein ${ }^{1}$ \\ ${ }^{1}$ Department of Biomedical Sciences, Faculty of Medicine and Health Sciences, An-Najah National University, Nablus, \\ P. O. Box. 7, State of Palestine \\ ${ }^{2}$ An-Najah National University Hospital, Nablus, P. O. Box. 7, State of Palestine \\ ${ }^{3}$ Department of Medicine, Faculty of Medicine and Health Sciences, An-Najah National University, Nablus, \\ P. O. Box. 7, State of Palestine
}

Correspondence should be addressed to Mohammad Qadi; m.qadi@najah.edu

Received 27 July 2021; Revised 30 November 2021; Accepted 2 December 2021; Published 13 December 2021

Academic Editor: Tingtao Chen

Copyright (c) 2021 Mohammad Qadi et al. This is an open access article distributed under the Creative Commons Attribution License, which permits unrestricted use, distribution, and reproduction in any medium, provided the original work is properly cited.

\begin{abstract}
Background. Maternal Streptococcus agalactiae (Group B Streptococcus (GBS)) colonization is an important cause of complications in mothers and neonates during gestation and after delivery. The data regarding GBS colonization among pregnant women in Palestine is scarce. The aim of this study is to determine the prevalence of GBS colonization, its associated risk factors, and the antibiotic sensitivity patterns in Nablus, West Bank, Palestine. Methods. A cross-sectional, single center study conducted at Rafidia Governmental Hospital in Nablus, West Bank, Palestine. Samples were collected between November 2019 and January 2020. Vaginal swabs from 200 pregnant women ( $\geq 35$ weeks of gestation) attending the labor and delivery department were plated directly on CHROMagar ${ }^{\text {TM }}$ StrepB (CHROM agar, France) and placed in an incubator at $35-37^{\circ} \mathrm{C}$. After 24 and 48 hours, the plates were checked for growth and classified into three categories: growth of GBS with mauve colonies on chromogenic media, no growth, or other growth. The identification of the mauve colonies was confirmed by the CAMP test. Identified GBS isolates were tested for susceptibility to vancomycin, ampicillin, clindamycin, cefotaxime, erythromycin, and levofloxacin using the disc diffusion method. Clinical and demographic information were collected using a questionnaire. Result. The overall prevalence of GBS colonization was $12 \%$. The median age of the study population was 27 years. GBS colonization was significantly associated with age $(p=0.013)$, history of previous preterm delivery $(p=0.013)$, and parity $(p=0.015)$. No association was noted with smoking, previous abortion, previous history of fetal demise, vaginitis, or urinary tract infection. Resistance to ampicillin, vancomycin, cefotaxime, erythromycin, clindamycin, and levofloxacin was found to be $91.7 \%, 54.2 \%, 45.8 \%, 29.2 \%, 25 \%$, and $8.3 \%$, respectively. Conclusion. The prevalence of vaginal GBS in this study was $12 \%$ from Nablus, West Bank. Further research is needed to determine the GBS serotypes common in West Bank and the burden they cause on the health system. Moreover, this study also highlights the need to establish a screening program suited to a developing country with low control on the antibiotic's prescription protocols.
\end{abstract}

\section{Introduction}

Streptococcus agalactiae, also known as Group B Streptococcus (GBS), is $\beta$-hemolytic Gram-positive cocci. It can be a constituent of the human normal flora [1], found asymptomatically in the maternal genital and gastrointestinal tracts. It is estimated that $18 \%$ of women worldwide are colonized with GBS [2].

GBS colonization in pregnant women has a significant clinical burden, and it has been identified as the primary risk factor for the development of early-onset GBS disease [3]. GBS can cause ascending infections which may lead to 
serious consequences for the mother and the baby during gestation and after delivery, including maternal sepsis, stillbirth, and neonatal death [4-6]. Around 4 out of every 10,000 pregnant women have GBS sepsis during their pregnancy [6], and a study in Ireland showed that GBS accounted for $25 \%$ of clinically significant bacteremia in hospitalized pregnant women [7]. Moreover, it has been reported that $1 \%$ of all stillbirths in developed countries and $4 \%$ of stillbirths in Africa are associated with GBS [5], and the odds of having a stillbirth in Eastern Ethiopia are 8.93 times higher among GBS-colonized pregnant women [8]. Worldwide, the case fatality rate for infants with GBS is estimated to be around $8.4 \%$ [4].

GBS is the most common cause of early-onset neonatal sepsis and meningitis $[9,10]$, and is also a major cause of preterm labor, premature rupture of membranes, chorioamnionitis, and bacteremia [10]. GBS colonization is also a known risk factor for the development of late-onset GBS infections, which commonly manifest as bacteremia without an apparent focus of infection [11]. These late-onset infections may also cause meningitis and may rarely lead to focal infections affecting bones, joints, soft tissue, or the urinary tract.

There are multiple risk factors associated with GBS colonization, including older maternal age, lower gestational age, length of premature rupture of membranes, midwife delivery, and experiencing meconium-stained amniotic fluid $[12,13]$.

The Centers for Disease Control and Prevention (CDC) recommends that all pregnant women between the $35^{\text {th }}$ and $37^{\text {th }}$ gestational weeks should be screened for vaginal-rectal GBS colonization and that those with positive swab cultures should receive intrapartum antibiotic prophylaxis (IAP). In addition, pregnant women with a previous infant with GBS disease, GBS bacteriuria in the current pregnancy, as well as those with unknown colonization status and intrapartum risk factors such as maternal fever or prolonged rupture of membranes are provided with IAP during labor [14]. In the absence of IAP, it is estimated that about $50 \%$ of newborn infants born to women colonized with GBS become colonized with GBS themselves, and of those, $1-2 \%$ will develop early-onset GBS disease [15].

The gold standard method for diagnosis of GBS colonization comprises culture of combined vaginal and rectal samples in a selective enrichment medium. There are two types of selective media for GBS, the Granada (anaerobic) medium and the Chrom ID $^{\mathrm{TM}}$ Strepto B medium (aerobic) (CHROM-B). Recent developments of real-time polymerase chain reaction (PCR) and fluorescence labelling technologies have provided new methods for bacterial identification [16]. GBS-specific PCR assays are highly sensitive and specific, but they are expensive [17].

In Palestine, there is no screening program for GBS colonization among pregnant women. To the best of our knowledge, there are no previous studies about Palestinian GBS colonization, except for a study in the Gaza Strip [18]. The objective of this study was to estimate the prevalence of GBS colonization in the city of Nablus, the associated risk factors for colonization, and the antibiotic susceptibility of the GBS isolates.

\section{Materials and Methods}

2.1. Study Design. A cross-sectional study was conducted over a period of 3 months.

2.2. Study Setting and Population. Parturient women attending Rafidia Governmental Hospital for vaginal delivery in the period extending from November 2019 to January 2020 were invited to participate in the study. Rafidia Hospital is the only major obstetric governmental hospital in Nablus, Palestine, with about 450-550 pregnant women admitted for delivery each month. Pregnant women on any antibiotic treatment in the last two weeks prior to data collection and those less than 35 weeks of gestation were excluded.

2.3. Questionnaire. Ladies who agreed to participate were interviewed face-to-face with a structured questionnaire which was prepared in the local language (Arabic). The questionnaire included gestational and demographic variables like maternal age, employment status, smoking, family income, place of residence, parity, and other pregnancyrelated characteristics like previous miscarriages, preterm labor, vaginal discharge, vaginal pruritus, vaginal burning, vulvitis, and vaginal candidiasis.

2.4. Sample Collection. Each swab was brushed against the posterior vaginal wall with the patient in the lithotomy position without the use of a speculum.

2.5. Isolation of GBS. The swabs were plated directly on CHROMagar ${ }^{\mathrm{TM}}$ StrepB (CHROMagar, France) and placed in an incubator at $35-37^{\circ} \mathrm{C}$. After 24 and 48 hours, the plates were checked for growth and classified into three categories: growth with mauve colonies on chromogenic media, no growth, or other growth. GBS identification was confirmed by performing a CAMP test on all growth with mauve colonies. A single straight-line streak of beta-hemolysin producing Staphylococcus aureus was made on a blood agar plate. Subsequently, a perpendicular streak of the beta-hemolytic Streptococcus was added to be identified. Then, the plates were incubated at $35^{\circ} \mathrm{C}$ in ambient air for 18-24 hours. Plates were observed for areas of increased hemolysis at the intersection of both streaks. The beta-hemolysin secreted by Staphylococcus and the CAMP factor secreted by group B Streptococcus resulted in an increased area of hemolysis.

2.6. Antibiotic Susceptibility. All confirmed GBS isolates were subcultured onto blood agar plates for 24 hours at $37^{\circ} \mathrm{C}$, and tested for susceptibility to vancomycin, ampicillin, clindamycin, cefotaxime, erythromycin, and levofloxacin using $\mathrm{BD} \mathrm{BBL}^{\mathrm{TM}}$ Sensi-Disc ${ }^{\mathrm{TM}}$ dispensers according to the CLSI Performance Standards for Antimicrobial Susceptibility Testing [19]. All recommended antibiotics from group A and group $B$ were tested, in addition to one antibiotic from group C. Ampicillin was used as an alternative to penicillin 
in susceptibility testing, in compliance with the aforementioned guidelines.

2.7. Statistical Analysis. Results were analyzed using the IBM Statistical Package for Social Sciences program (SPSS) version 21. The relationships between categorical variables were analyzed using the Chi-square test for small cell sizes $(n<5)$. A $p$ value of less than 0.05 was considered significant. For continuous variables, data were expressed as median \pm SD. Categorical variables were expressed as frequencies and percentages.

2.8. Ethical Considerations. Approval was obtained from the Institutional Review Board (IRB) of An-Najah National University and from the Ministry of Health. A written informed consent was obtained from all participants.

\section{Results}

3.1. Patient Characteristics. 200 women who presented with labor between November 2019 and January 2020 to Rafidia Governmental Hospital participated in the study; their demographic and clinical characteristics are displayed in Table 1 . The median age of participants was 27 years, $61.5 \%$ were city residents, and about half (58\%) of them had an income between 3500 and 5000 shekels. Two-thirds (76\%) of the women had been pregnant before, and a few $(8.5 \%)$ reported cigarette smoking.

3.2. GBS Colonization. The overall prevalence of GBS colonization as determined by chromogenic culture and confirmed by the CAMP test was $12 \%$. Most $(83.3 \%)$ of the colonized women were between 25 and 33 years old, while $4.2 \%$ were younger than 25 years and $12.5 \%$ were older than 33 years. The frequency of GBS colonization among different age groups was statistically significant $(p<0.05)$. The age groups of GBS-colonized and noncolonized women are shown in Table 2.

3.3. Risk Factors. Different factors associated with GBS colonization are outlined in Table 3 . There was no significant difference between GBS-colonized women and noncolonized women in terms of symptoms of vaginal infections $(p>0.05)$ nor in symptoms of urinary tract infections $(p>0.05)$. In addition, there was no significant difference in smoking status between the two groups $(p>0.05)$.

This study's data showed a significant difference regarding previous preterm delivery $(p=0.013)$ and previous pregnancy $(p=0.015)$. However, no statistically significant difference was observed with a history of previous abortion in the first or second trimester $(29.9 \%$ and $0.0 \%$, respectively) or with fetal demise $(4.2 \%)(p>0.05)$.

3.4. Antimicrobial Susceptibilities of GBS. Of the 24 examined GBS isolates, $16(66.7 \%)$ were susceptible to levofloxacin, 14 isolates (58.3\%) to clindamycin, $13(54.2 \%)$ to
TABLE 1: Sociodemographic characteristics of participants.

\begin{tabular}{lc}
\hline Characteristics & $N(\%)$ \\
\hline Age (years) & $27^{\mathrm{a}}(8)^{\mathrm{b}}$ \\
$16-24$ years & $52(26 \%)$ \\
$25-33$ years & $125(62.5 \%)$ \\
34 years and older & $23(11.5 \%)$ \\
\hline Income (Israeli shekels) & \\
$\quad<2500$ & $4(2 \%)$ \\
$2500-3500$ & $72(36 \%)$ \\
$3500-5000$ & $116(58 \%)$ \\
$>5000$ & $8(4 \%)$ \\
\hline Residence & \\
City & $123(61.5 \%)$ \\
Village & $77(38.5 \%)$ \\
\hline Prior history of pregnancy & $152(76 \%)$ \\
Yes & $48(24 \%)$ \\
$\quad$ No & \\
\hline Smoker & $17(8.5 \%)$ \\
$\quad$ Yes & $183(91.5 \%)$ \\
$\quad$ No &
\end{tabular}

${ }^{\mathrm{a}}$ Median; ${ }^{\mathrm{b}}$ standard deviation.

cefotaxime, $11(45.8 \%)$ to each vancomycin and erythromycin, and $2(8.3 \%)$ to ampicillin, as shown in Table 4.

\section{Discussion}

4.1. Prevalence of GBS among Pregnant Women. GBS colonization in pregnant women carries a significant clinical burden, as it is associated with maternal and fetal morbidity and mortality. One meta-analysis showed that overall, $18 \%$ of women worldwide are colonized with GBS, with regional variation in prevalence $(11 \%-35 \%)$ [20]. In this study, the prevalence of GBS colonization was $12 \%$, similar to another study conducted in southern Israel which showed a prevalence of $12.3 \%$ [21], while other studies conducted in Gaza and Nazareth showed a higher prevalence of GBS colonization ( $21 \%$ and $31 \%$, respectively) $[18,22]$. Similarly, surrounding countries had a higher prevalence of colonization; $27.4 \%, 19.5 \%$, and $18.4 \%$ in Egypt [23], Jordan [24], and Lebanon [25], respectively. The differences in the colonization rate could be attributed in part to specimen collection methods and lab-related causes. Table 5 summarizes the methods used in the studies describing the GBS colonization rate in the vicinities of the West Bank.

The prevalence rates of GBS colonization vary in different geographical regions across the globe. This study showed similar results to those of other studies in Saudi Arabia [26], Tunisia [27], and China [28]. However, studies from Kuwait [29], Morocco [30], Iran [31], Turkey [32], and Ethiopia [33] reported higher prevalence rates than those found in this study. Meanwhile, on the other hand, lower prevalence rates were reported in India [34] and South Korea [35].

GBS colonization rates are affected by a number of patient and environmental characteristics, including race, origin, age, parity, socioeconomic status, diet, climate, and maternal hygiene. Colonization rates are also affected by the 
TABLE 2: Age groups of GBS-colonized and noncolonized women.

\begin{tabular}{lccc}
\hline & GBS-colonized women & Noncolonized women & $p$ value \\
\hline Age (years) & $28^{\mathrm{a}}(7)^{\mathrm{b}}$ & $27^{\mathrm{a}}(8)^{\mathrm{b}}$ & 0.031 \\
$16-24$ years & $1(4.2 \%)$ & $51(29 \%)$ & 0.009 \\
$25-33$ years & $20(83.3 \%)$ & $105(59.7 \%)$ & 0.025 \\
34 years and older & $3(12.5 \%)$ & $20(11.4 \%)$ & 0.87 \\
\hline
\end{tabular}

${ }^{\mathrm{a}}$ Median; ${ }^{\mathrm{b}}$ standard deviation.

TABLE 3: The medical history of both GBS-colonized and noncolonized pregnant women.

\begin{tabular}{|c|c|c|c|}
\hline & GBS-colonized women $(N)(\%)$ & Noncolonized women $(N)(\%)$ & $p$ value \\
\hline Smoker & $3(12.5 \%)$ & $14(8 \%)$ & 0.436 \\
\hline Previous pregnancy & $23(95.8 \%)$ & $129(73.3 \%)$ & 0.015 \\
\hline One pregnancy & $7(29.16 \%)$ & $26(14.8 \%)$ & 0.026 \\
\hline 2-3 pregnancies & $7(29.16 \%)$ & $53(30.1 \%)$ & 0.981 \\
\hline$\geq 4$ pregnancies & $9(37.5 \%)$ & $50(28.4 \%)$ & 0.744 \\
\hline Previous preterm ${ }^{\mathrm{a}}$ & $5(20.8 \%)$ & $11(6.3 \%)$ & 0.013 \\
\hline \multicolumn{4}{|l|}{ Number of abortions } \\
\hline 0 & $16(66.7 \%)$ & $144(81.8 \%)$ & 0.082 \\
\hline 1 & $7(29.2 \%)$ & $29(16.5 \%)$ & 0.129 \\
\hline$\geq 2$ & $1(4.2 \%)$ & $3(1.7 \%)$ & 0.403 \\
\hline \multicolumn{4}{|l|}{ Time of abortion } \\
\hline First trimester ${ }^{\mathrm{b}}$ & $7(29.2 \%)$ & $35(19.9 \%)$ & 0.295 \\
\hline Second trimester ${ }^{c}$ & $0(0.0 \%)$ & $8(4.5 \%)$ & 0.599 \\
\hline Fetal demise $^{\mathrm{d}}$ & $1(4.2 \%)$ & $1(0.6 \%)$ & 0.226 \\
\hline UTI symptoms ${ }^{\mathrm{e}}$ & $8(33.3 \%)$ & $44(25 \%)$ & 0.383 \\
\hline Vaginal infection symptoms ${ }^{\mathrm{f}}$ & $7(29.2 \%)$ & $40(22.7 \%)$ & 0.485 \\
\hline
\end{tabular}

UTI: urinary tract infection, abortion: fetal death before 24 weeks of gestation, ${ }^{a}$ delivery before 37 weeks of gestation, ${ }^{b}$ the first 12 weeks of gestation, ${ }^{c}$ from 13 weeks to 28 weeks of gestation, ${ }^{\mathrm{d}}$ death of a fetus after 24 gestational weeks, ${ }^{\mathrm{e}}$ urinary frequency, urgency, dysuria, ${ }^{\mathrm{f}}$ increased or foul-smelling vaginal discharge, burning, or itching.

TABle 4: Antibiotic susceptibilities of 24 GBS isolates from colonized pregnant women.

\begin{tabular}{lccc}
\hline Antibiotic & Sensitive, $N(\%)$ & Intermediate, $N(\%)$ & Resistant, $N(\%)$ \\
\hline Erythromycin & $11(45.8 \%)$ & $6(25 \%)$ & $7(29.2 \%)$ \\
Ampicillin & $2(8.3 \%)$ & - & $22(91.7 \%)$ \\
Vancomycin & $11(45.8 \%)$ & - & $13(54.2 \%)$ \\
Levofloxacin & $16(66.7 \%)$ & $6(25 \%)$ & $2(8.3 \%)$ \\
Cefotaxime & $13(54.2 \%)$ & - & $11(45.8 \%)$ \\
Clindamycin & $14(58.3 \%)$ & $4(16.7 \%)$ & $6(25 \%)$ \\
\hline
\end{tabular}

TABLE 5: Studies describing the GBS colonization rate in the vicinities of the West Bank.

\begin{tabular}{|c|c|c|c|c|c|c|c|}
\hline First author & Year & Location & Sample population & $\begin{array}{l}\text { Sample } \\
\text { size }\end{array}$ & $\begin{array}{l}\text { Collection } \\
\text { method }\end{array}$ & Confirmation method & $\begin{array}{l}\text { Colonization } \\
\text { rate }(\%)\end{array}$ \\
\hline $\begin{array}{l}\text { Qadi (this } \\
\text { study) }\end{array}$ & 2020 & $\begin{array}{l}\text { Nablus, West } \\
\text { Bank, Palestine }\end{array}$ & $\begin{array}{l}\text { Pregnant women (>35 } \\
\text { weeks' gestation) }\end{array}$ & 200 & Vaginal & CAMP test & 12 \\
\hline $\begin{array}{l}\text { Marchaim } \\
\text { et al. [21] }\end{array}$ & 2003 & Southern Israel & $\begin{array}{l}\text { Pregnant women }(>35 \\
\text { weeks' gestation) }\end{array}$ & 681 & $\begin{array}{l}\text { Vaginal and } \\
\text { rectal }\end{array}$ & $\begin{array}{l}\text { CAMP test and } \\
\text { agglutination test }\end{array}$ & 12.3 \\
\hline Nabil et al. [18] & 2017 & Gaza, Palestine & $\begin{array}{l}\text { Pregnant women (>35 } \\
\text { weeks' gestation) }\end{array}$ & 200 & $\begin{array}{l}\text { Vaginal and } \\
\text { rectal }\end{array}$ & PCR test & 21 \\
\hline $\begin{array}{l}\text { Clouse et al. } \\
\text { [24] }\end{array}$ & 2019 & Jordan & $\begin{array}{l}\text { Pregnant women (>35 } \\
\text { weeks' gestation) }\end{array}$ & 200 & $\begin{array}{l}\text { Vaginal and } \\
\text { rectal }\end{array}$ & Latex agglutination & 19.5 \\
\hline $\begin{array}{l}\text { Hakim et al. } \\
{[22]}\end{array}$ & 2018 & $\begin{array}{l}\text { Nazareth Arab- } \\
\text { Israeli }\end{array}$ & $\begin{array}{l}\text { Pregnant women (>35 } \\
\text { weeks' gestation) }\end{array}$ & 188 & $\begin{array}{l}\text { Vaginal and } \\
\text { rectal }\end{array}$ & $\begin{array}{l}\text { (AmpliVue }{ }^{\circledR} \text { GBS } \\
\text { assay), atoB gene }\end{array}$ & 31 \\
\hline $\begin{array}{l}\text { Shabayek et al. } \\
\text { [23] }\end{array}$ & 2013 & Egypt & $\begin{array}{c}\text { Pregnant and } \\
\text { nonpregnant women }\end{array}$ & 364 & Vaginal & PCR & 27.4 \\
\hline $\begin{array}{l}\text { Ghaddar et al. } \\
\text { [25] }\end{array}$ & 2014 & Lebanon & $\begin{array}{l}\text { Pregnant women (>35 } \\
\text { weeks' gestation) }\end{array}$ & 168 & Vaginal & Latex agglutination & 18.4 \\
\hline
\end{tabular}


medium used and the number and type of sites that have been cultured $[36,37]$. Using vaginal swabs only as a collection method has been shown to lower the prevalence of GBS colonization for the same population. This was exemplified in a study in Ethiopia, in which the overall carriage rate was $19 \%$ while the vaginal carriage rate was $10.4 \%$ [33]. In addition, in a study in Iran, the frequency of GBS-positive culture results from rectal samples was higher than that using vaginal samples only [31]. After initial detection of GBS colonies, the confirmation method also seems to play a role in the reported GBS colonization rate. That is, the more specific the confirmation method, the lower the reported GBS colonization rate, and the more sensitive the confirmation method, the higher the reported GBS colonization rate. For instance, a study in Iran mentioned that the use of PCR confirmed higher positive results for GBS than culture confirmation techniques due to the high sensitivity of PCR [31].

Although culturing on CHROMagar followed by CAMP test confirmation gave the comparable prevalence of $12 \%$, the PCR technique may fine the prevalence as it is a more sensitive technique. In addition, one source of the samples from vaginal swamps may underestimate the prevalence that may be modified with the simultaneous vaginal and rectal samples; therefore, the prevalence may be greater than that obtained from vaginal samples only.

4.2. Risk Factors. In this study, women with a history of preterm delivery had a significantly higher frequency of GBS colonization. Similar findings have been reported in studies conducted among Danish women [38] and Canadian women [39]. This is presumably because women colonized with GBS at delivery are more likely to have a preterm delivery than women who were not colonized [38]. In contrast, studies among Australian women showed no association between preterm delivery and GBS colonization [40].

With the exception of age and parity, no statistically significant association was observed between GBS colonization and any sociodemographic characteristics in our study. This may be in part due to the small sample size and the large number of variables included as sociodemographic characteristics. These results are similar to a study conducted in Brazil, which concluded that GBS colonization does not appear to be directly related to socioeconomic factors [41], and a study conducted in Iran [42], where there were no significant differences in colonization rates based on age or parity. In contrast, increasing age or parity in some studies in Tanzania has been shown to be associated with increased GBS colonization [43].

Contrary to our results, an Australian study [44] demonstrated an association between GBS colonization and spontaneous abortions. Meanwhile, our findings confirm those of another study in Tanzania [43], in which there was no association found between GBS colonization rate and spontaneous abortions.

While our study found no association between urinary tract infections during pregnancy and GBS colonization, a study from the Democratic Republic of the Congo found that they were associated with a high odds ratio for vaginal colonization [45], similar to results found in Korea [46].

We also reported no association between GBS colonization and vaginitis, in contrast to a Tunisian study [47]. Moreover, no association between colonization with GBS and smoking was found in this study, while studies in Iran [48] and the USA [49] demonstrated an association. Numerous factors play a role in these differences of reporting associations in each study, and we suspect that a small sample size, among other variables, contributes to this difference.

4.3. Antibiotic Sensitivity. Antibiotic resistance is a growing problem worldwide, and GBS is no exception. In the present study, the rate of resistance to ampicillin was very high (91.7\%), while mildly reduced susceptibility to ampicillin was found in a study in Ethiopia [50], and no resistance to ampicillin was found in studies conducted in Saudi Arabia [26] and Cameroon [36].

High rates of vancomycin resistance have been detected in our study (54.2\%). In contrast, $100 \%$ susceptibility was found in other studies conducted in the USA [51] and in Brazil [52].

The high resistance of GBS isolates in our study to ampicillin and vancomycin is possibly because of the widespread empiric use of antibiotics for the treatment of different infectious diseases, and the availability of these drugs nonrestrictively and inexpensively in different areas enables self-prescription.

In contrast to our study, where $45.8 \%$ of GBS isolates were resistant to cefotaxime, $100 \%$ susceptibility was detected in studies conducted in the USA [53] and in Brazil [54]. Moreover, resistance in our study to erythromycin and clindamycin was $29.2 \%$ and $25 \%$, respectively, which is significantly higher than recent studies conducted in Kuwait [55] and in Tanzania [43]. As for levofloxacin, it had the highest susceptibility rate in this study, closer to the results documented in a study in Argentina [56].

\section{Conclusion}

This research was the first to be conducted in the West Bank regarding GBS colonization in pregnant women. The prevalence of GBS in this study was $12 \%$, and further research is needed to determine the common GBS serotypes in the West Bank and the burden they may cause on the health system. This study also highlights the need to establish a screening program suited to a developing country, with consideration given to the growing problem of antibiotic resistance.

\subsection{Limitations}

(i) Most participants refused rectal swabs, so only vaginal swabs were obtained

(ii) As a cross-sectional study, the causal relationship cannot be assessed 
(iii) The study did not assess the serotypes of GBS in colonized women

\section{Data Availability}

The data used to support the findings of this study are included within the article.

\section{Conflicts of Interest}

The authors declare that they have no conflicts of interest.

\section{Acknowledgments}

The authors would like to acknowledge the Faculty of Medicine and Health Sciences at An-Najah National University for facilitating the accomplishment of the current study. The authors are also thankful to the Palestinian Ministry of Health and Rafidia Hospital for taking part in this study. This study was funded by An-Najah National University, as it was in part a graduation project for students in the Department of Medicine.

\section{References}

[1] A. C. Seale, H. Blencowe, F. Bianchi-Jassir et al., "Stillbirth with group B Streptococcus disease worldwide: systematic Review and meta-analyses," Clinical Infectious Diseases, vol. 65, no. suppl_2, pp. S125-s132, 2017.

[2] A. C. Seale, F. Bianchi-Jassir, N. J. Russell et al., "Estimates of the burden of group B streptococcal disease worldwide for pregnant women, stillbirths, and children," Clinical Infectious Diseases, vol. 65, no. suppl_2, pp. S200-S219, 2017.

[3] M. M. Ali, D. Asrat, D. A. Fenta, T. E. Chaka, and Y. Woldeamanuel, "Group B Streptococcus colonization rate and serotype distribution among pregnant women and their newborns at Adama Hospital Medical College, Ethiopia," Scientific Reports, vol. 10, no. 1, p. 9301, 2020.

[4] L. Madrid, A. C. Seale, M. Kohli-Lynch et al., "Infant group B streptococcal disease incidence and serotypes worldwide: systematic Review and meta-analyses," Clinical Infectious Diseases, vol. 65, no. suppl_2, pp. S160-S172, 2017.

[5] J. E. Lawn, F. Bianchi-Jassir, N. J. Russell et al., "Group B streptococcal disease worldwide for pregnant women, stillbirths, and children: why, what, and how to undertake estimates?" Clinical Infectious Diseases, vol. 65, no. suppl_2, pp. S89-S99, 2017.

[6] J. Hall, N. H. Adams, L. Bartlett et al., "Maternal disease with group B Streptococcus and serotype distribution worldwide: systematic Review and meta-analyses," Clinical Infectious Diseases, vol. 65, no. suppl_2, pp. S112-S124, 2017.

[7] R. J. Drew, Z. Fonseca-Kelly, and M. Eogan, "A retrospective audit of clinically significant maternal bacteraemia in a specialist maternity hospital from 2001 to 2014," Infectious Diseases in Obstetrics and Gynecology, vol. 2015, Article ID 518562, 2015.

[8] T. A. Yadeta, A. Worku, G. Egata, B. Seyoum, D. Marami, and Y. Berhane, "Maternal group B Streptococcus recto vaginal colonization increases the odds of stillbirth: evidence from Eastern Ethiopia," BMC Pregnancy and Childbirth, vol. 18, no. 1, p. 410, 2018.
[9] K. A. Simonsen, A. L. Anderson-Berry, S. F. Delair, and H. D. Davies, "Early-onset neonatal sepsis," Clinical Microbiology Reviews, vol. 27, no. 1, pp. 21-47, 2014.

[10] V. N. Raabe and A. L. Shane, "Group B Streptococcus (Streptococcus agalactiae)," Microbiology Spectrum, vol. 7, no. 2, 2019.

[11] A. Berardi, V. Trevisani, A. Di Caprio et al., "Understanding factors in group B Streptococcus late-onset disease," Infection and Drug Resistance, vol. 14, pp. 3207-3218, 2021.

[12] A. C. N. Botelho, J. G. Oliveira, A. P. Damasco et al., "Streptococcus agalactiae carriage among pregnant women living in Rio de Janeiro, Brazil, over a period of eight years," PLoS One, vol. 13, no. 5, Article ID e0196925, 2018.

[13] M. Gizachew, M. Tiruneh, F. Moges, M. Adefris, Z. Tigabu, and B. Tessema, "Streptococcus agalactiae from Ethiopian pregnant women; prevalence, associated factors and antimicrobial resistance: alarming for prophylaxis," Annals of Clinical Microbiology and Antimicrobials, vol. 18, no. 1, p. 3, 2019.

[14] K. Le Doare, M. O’Driscoll, K. Turner et al., "Intrapartum antibiotic chemoprophylaxis policies for the prevention of group B streptococcal disease worldwide: systematic Review," Clinical Infectious Diseases, vol. 65, no. suppl_2, pp. S143S151, 2017.

[15] K. M. Puopolo, R. Lynfield, and J. J. Cummings, "Management of infants at risk for group B streptococcal disease," Pediatrics, vol. 144, no. 2, Article ID e20191881, 2019.

[16] D. L. Church, H. Baxter, T. Lloyd, O. Larios, and D. B. Gregson, "Evaluation of StrepB select chromogenic medium and the fast-track diagnostics group B Streptococcus (GBS) real-time PCR assay compared to routine culture for detection of GBS during antepartum screening," Journal of Clinical Microbiology, vol. 55, no. 7, pp. 2137-2142, 2017.

[17] D. H. Kim, B. J. Min, E. J. Jung et al., "Prevalence of group B streptococcus colonization in pregnant women in a tertiary care center in Korea," Obstetrics \& Gynecology Science, vol. 61, no. 5, pp. 575-583, 2018.

[18] A. Nabil, S. E. Esleem, and A. A. Elmanama, "Prevalence of group B streptococcus colonization among pregnant women in Gaza strip, Palestine," IUG Journal of Natural Studies, vol. 25, no. 3, 2017.

[19] F. R. Cockerill, Performance Standards for Antimicrobial Susceptibility Testing: Twenty-First Informational Supplement, Clinical and Laboratory Standards Institute (CLSI), Wayne, PA, USA, 2011.

[20] N. J. Russell, A. C. Seale, M. O’Driscoll et al., "Maternal colonization with group B Streptococcus and serotype distribution worldwide: systematic Review and meta-analyses," Clinical Infectious Diseases, vol. 65, no. suppl_2, pp. S100S111, 2017.

[21] D. Marchaim, M. Hallak, L. Gortzak-Uzan, N. Peled, K. Riesenberg, and F. Schlaeffer, "Cell wall proteins of group B Streptococcus and low incidence of neonatal disease in southern Israel," Journal of Reproductive Medicine, vol. 48, no. 9, pp. 697-702, 2003.

[22] M. Hakim, A. Jabour, M. Anton, M. Hakim, and S. Kheirallah, "Screening arab Israeli pregnant women for group B Streptococcus by the AmpliVue GBS assay: are the rates higher than the national average?" The Israel Medical Association Journal: The Israel Medical Association Journal, vol. 20, no. 5, pp. 291-294, 2018.

[23] S. Shabayek, S. Abdalla, and A. M. Abouzeid, "Serotype and surface protein gene distribution of colonizing group B 
streptococcus in women in Egypt," Epidemiology and Infection, vol. 142, no. 1, pp. 208-210, 2013.

[24] K. Clouse, A. Shehabi, A. M. Suleimat et al., "High prevalence of Group B Streptococcus colonization among pregnant women in Amman," Jordan, vol. 19, no. 1, p. 177, 2019.

[25] N. Ghaddar, W. Alfouzan, E. Anastasiadis et al., "Evaluation of chromogenic medium and direct latex agglutination test for detection of group B streptococcus in vaginal specimens from pregnant women in Lebanon and Kuwait," Journal of Medical Microbiology, vol. 63, no. Pt 10, pp. 1395-1399, 2014.

[26] M. A. Khan, A. Faiz, and A. M. Ashshi, "Maternal colonization of group B streptococcus: prevalence, associated factors and antimicrobial resistance," Annals of Saudi Medicine, vol. 35, no. 6, pp. 423-427, 2015.

[27] M. Jerbi, S. Hidar, N. Hannachi et al., "Risk factors for group B streptococcal colonization in pregnant women at term: prospective study of 294 cases," Gynecologie Obstetrique \& Fertilite, vol. 35, no. 4, pp. 312-316, 2007.

[28] Y. Zhu, J. Huang, X. Z. Lin, and C. Chen, "Group B Streptococcus colonization in late pregnancy and invasive infection in neonates in China: a population-based 3-year study," Neonatology, vol. 115, no. 4, pp. 301-309, 2019.

[29] N. Al-Sweih, S. Maiyegun, M. Diejomaoh et al., "Streptococcus agalactiae (Group B Streptococci) carriage in late pregnancy in Kuwait," Medical Principles and Practice, vol. 13, no. 1, pp. 10-14, 2004.

[30] A. Bassir, H. Dhibou, M. Farah et al., "Vaginal colonization by group B streptococcus among pregnant women in the region of Marrakech," Pan African Medical Journal, vol. 23, p. 107, 2016.

[31] S. Bidgani, T. Navidifar, M. Najafian, and M. Amin, "Comparison of group B streptococci colonization in vaginal and rectal specimens by culture method and polymerase chain reaction technique," Journal of the Chinese Medical Association, vol. 79, no. 3, pp. 141-145, 2016.

[32] A. Kadanali, U. Altoparlak, and S. Kadanali, "Maternal carriage and neonatal colonisation of group B streptococcus in eastern Turkey: prevalence, risk factors and antimicrobial resistance," International Journal of Clinical Practice, vol. 59, no. 4, pp. 437-440, 2005.

[33] A. Mengist, H. Kannan, and A. Abdissa, "Prevalence and antimicrobial susceptibility pattern of anorectal and vaginal group B Streptococci isolates among pregnant women in Jimma, Ethiopia," BMC Research Notes, vol. 9, p. 351, 2016.

[34] S. Santhanam, R. Jose, R. D. Sahni, N. Thomas, and M. M. Beck, "Prevalence of group B Streptococcal colonization among pregnant women and neonates in a tertiary hospital in India," Journal of the Turkish-German Gynecological Association, vol. 18, no. 4, pp. 181-184, 2017.

[35] B. K. Lee, Y. R. Song, M. Y. Kim et al., "Epidemiology of group B streptococcus in Korean pregnant women," Epidemiology and Infection, vol. 138, no. 2, pp. 292-298, 2010.

[36] N. M. Nkembe, H. G. Kamga, W. A. Baiye, A. B. Chafa, and P. N. Njotang, "Streptococcus agalactiae prevalence and antimicrobial susceptibility pattern in vaginal and anorectal swabs of pregnant women at a tertiary hospital in Cameroon," BMC Research Notes, vol. 11, no. 1, p. 480, 2018.

[37] M. Quiroga, E. Pegels, P. Oviedo, E. Pereyra, and M. Vergara, "Antibiotic susceptibility patterns and prevalence of group B Streptococcus isolated from pregnant women in Misiones, Argentina," Brazilian Journal of Microbiology, vol. 39, pp. 245-250, 2008.

[38] D. R. Feikin, P. Thorsen, S. Zywicki, M. Arpi, J. G. Westergaard, and A. Schuchat, "Association between colonization with group B streptococci during pregnancy and preterm delivery among Danish women," American Journal of Obstetrics and Gynecology, vol. 184, no. 3, pp. 427-433, 2001.

[39] U. Allen, C. Nimrod, N. Macdonald, B. Toye, D. Stephens, and V. Marchessault, "Relationship between antenatal group B streptococcal vaginal colonization and premature labour," Paediatrics and Child Health, vol. 4, no. 7, pp. 465-469, 1999.

[40] S. M. Garland, N. Kelly, and A. M. Ugoni, "Is antenatal group B streptococcal carriage a predictor of adverse obstetric outcome?" Infectious Diseases in Obstetrics and Gynecology, vol. 8, no. 3-4, pp. 138-142, 2000.

[41] A. S. Zusman, R. S. Baltimore, and S. N. Fonseca, "Prevalence of maternal group B streptococcal colonization and related risk factors in a Brazilian population," Brazilian Journal of Infectious Diseases, vol. 10, no. 4, pp. 242-246, 2006.

[42] S. Mansouri, "Vaginal colonization of Group B Streptococci during late pregnancy in southeast of Iran: incidence, serotype distribution and susceptibility to antibiotics," Journal of Medical Science, vol. 8, no. 6, pp. 574-578, 2008.

[43] A. Joachim, M. I. Matee, F. A. Massawe, and E. F. Lyamuya, "Maternal and neonatal colonisation of group B streptococcus at Muhimbili National Hospital in Dar es Salaam, Tanzania: prevalence, risk factors and antimicrobial resistance," $B M C$ Public Health, vol. 9, p. 437, 2009.

[44] H. M. McDonald and H. M. Chambers, "Intrauterine infection and spontaneous midgestation abortion: is the spectrum of microorganisms similar to that in preterm labor?" Infectious Diseases in Obstetrics and Gynecology, vol. 8, no. 56, pp. 220-227, 2000.

[45] T. Kashosi, S. Ntamako, A. Muhandule Birindwa et al., "Prevalence of colonization by Streptococcus agalactiae among pregnant women in Bukavu, Democratic Republic of the Congo," Journal of infection in developing countries, vol. 8, pp. 1195-1200, 2014.

[46] E. J. Kim, K. Y. Oh, M. Y. Kim et al., "Risk factors for group B streptococcus colonization among pregnant women in Korea," Epidemiology and health, vol. 33, Article ID e2011010, 2011.

[47] A. Ferjani, H. Ben Abdallah, N. Ben Saida, C. Gozzi, and J. Boukadida, "Vaginal colonization of the Streptococcus agalactiae in pregnant woman in Tunisia: risk factors and susceptibility of isolates to antibiotics," Bulletin de la Société de Pathologie Exotique, vol. 99, no. 2, pp. 99-102, 2006.

[48] R. Darabi, S. Tadi, M. Mohit et al., "The prevalence and risk factors of group B streptococcus colonization in Iranian pregnant women," Electronic Physician, vol. 9, no. 5, pp. 4399-4404, 2017.

[49] R. R. Terry, F. W. Kelly, C. Gauzer, and M. Jeitler, "Risk factors for maternal colonization with group B beta-hemolytic streptococci," Journal of the American Osteopathic Association, vol. 99, no. 11, pp. 571-573, 1999.

[50] S. Assefa, K. Desta, and T. Lema, "Group B streptococci vaginal colonization and drug susceptibility pattern among pregnant women attending in selected public antenatal care centers in Addis Ababa, Ethiopia," BMC Pregnancy and Childbirth, vol. 18, no. 1, p. 135, 2018.

[51] B. R. Berg, J. L. Houseman, Z. E. terSteeg, W. D. LeBar, and D. W. Newton, "Antimicrobial susceptibilities of group B streptococcus isolates from prenatal screening samples," Journal of Clinical Microbiology, vol. 52, no. 9, pp. 3499-3500, 2014.

[52] D. S. Castellano-Filho, V. L. da Silva, T. C. Nascimento, M. de Toledo Vieira, and C. G. Diniz, "Detection of Group B Streptococcus in Brazilian pregnant women and antimicrobial 
susceptibility patterns," Brazilian Journal of Microbiology, vol. 41, no. 4, pp. 1047-1055, 2010.

[53] F.-Y. C. Lin, P. H. Azimi, L. E. Weisman et al., "Antibiotic susceptibility profiles for group B streptococci isolated from neonates, 1995-1998," Clinical Infectious Diseases, vol. 31, no. 1, pp. 76-79, 2000.

[54] S. C. C. Melo, N. Santos, M. Oliveira et al., "Antimicrobial susceptibility of streptococcus agalactiae isolated from pregnant women," Revista do Instituto de Medicina Tropical de Sao Paulo, vol. 58, p. 83, 2016.

[55] S. S. Boswihi, E. E. Udo, and N. Al-Sweih, "Serotypes and antibiotic resistance in Group B streptococcus isolated from patients at the Maternity Hospital, Kuwait," Journal of Medical Microbiology, vol. 61, no. Pt 1, pp. 126-131, 2012.

[56] M. Quiroga, E. Pegels, P. Oviedo, E. Pereyra, and M. Vergara, "Antibiotic susceptibility patterns and prevalence of group B Streptococcus isolated from pregnant women in Misiones, Argentina," Brazilian Journal of microbiology: [publication of the Brazilian Society for Microbiology], vol. 39, no. 2, pp. 245-250, 2008. 